\title{
Mental Toughness in Collegiate Strength and Conditioning: Widely Used, Widely Misunderstood
}

\author{
Andreas Stamatis ${ }^{1}$, Eric L. Robinson ${ }^{2} \&$ Grant B. Morgan ${ }^{2}$ \\ ${ }^{1}$ Sport and Wellness, SUNY Plattsburgh, Plattsburgh, NY, USA \\ ${ }^{2}$ Educational Psychology, Baylor University, Waco, TX, USA \\ Correspondence: Andreas Stamatis, Department of Sport and Wellness, SUNY Plattsburgh, Memorial Hall 301A, \\ 101 Broad Street, Plattsburgh, NY, 12901-2681, USA. Tel: 1-518-564-4337. E-mail: coach_stam@rocketmail.com
}

Received: March 30, 2018

Accepted: April 18, 2018

Online Published: April 23, 2018

doi:10.5430/irhe.v3n2p35

URL: https://doi.org/10.5430/irhe.v3n2p35

\begin{abstract}
Researchers explored the value of mental toughness (MT) for strength and conditioning coaches (SCC) for women's basketball of a NCAA Division I conference. Eight SCCs completed a questionnaire and six participated in a semi-structured interview. Results showed that, while there is no agreement whether MT can be developed in student-athletes or about its key attributes, all coaches believe MT is of value. Further, none of the participants reported being aware of or using an instrument to measure MT. Conclusions are that MT is a widely-used but relatively unclear construct. Future research should focus on definition, measurement, and implementation issues.
\end{abstract}

Keywords: mentally tough, performance psychology, NCAA, NSCA, CSCCa

\section{Introduction}

“Our strength and conditioning program develops character, mental toughness..."

(West Virginia University, 2015)

"The OU basketball strength and conditioning program is centered around three goals: improving performance on the court, decreasing injury, and increasing mental toughness..."

(Oklahoma State University, 2015)

"The strength and conditioning coaches not only enhance each athlete's athletic ability, but provide an environment conducive to the development of discipline and leadership skills for reaching optimum physical potential and mental toughness." (Oklahoma University, 2007)

The concept of mental toughness (MT) is closely related to the construct of positive psychology (Seligman \& Csikszentmihalyi, 2014) and the term was popularized in the 1980s (Loehr, 1986). A review of the extant literature can easily reveal the following:

- MT is a term that becomes more popular in sports by the day, even in strength and conditioning (see examples above);

- Despite the increased interest and attention, MT remains both one of the most accepted (Dohme, Backhouse, Piggott, \& Morgan, 2017) and misunderstood terms in applied sports psychology (Gucciardi, Zhang, Ponnusamy, $\mathrm{Si}$, \& Stenling, 2016);

- MT has been predominantely investigated in male sports (e.g., Gucciardi, Gordon, \& Dimmock, 2009) and when it comes to strength and conditioning, research is extremely limited (e.g., Radcliffe, Comfort, \& Fawcett, 2013);

- There is no consensus in the literature about whether MT is hereditary (e.g., Nicholls, Polman, Levy, \& Backhouse, 2009), can be developed (e.g., Gibson, 1998) and in what age (e.g., Dohme et al., 2017), or both (e.g., Jones, Hanton, \& Connaughton, 2002); and

- There are unsolved issues concerning implementation (lack of empirically-based practices; Gucciardi, Gordon, Dimmock, \& Mallett, 2009) and measurement (need for psychometricall-sound instruments; Gucciardi \& Gordon, 2009; Mack \& Ragan, 2008; Sheard, Golby, \& van Wersch, 2009).

In order to address the main points adressed above, a study to investigate the beliefs of strength and conditioning coaches (SSC) of women's collegiate basketball in regards to MT was conducted (Stamatis, Robinson, \& Morgan, 
2017). Specifically, using a convergent design and based on the literature, field tendencies, and practice, seven areas of interest were explored:

\section{How do SCCs define MT?}

2. What is their opinion about the value of MT?

3. Can MT be developed in student-athletes?

4. Are they implementing any type of MT?

5. Do they believe there are gender differences in the development of MT?

6. Do they think that there are any differences in the responsibilities to develop MT between the SCCs and basketball coaches (BC)/head coaches (HC)? and

7. Would they be interested in learning more about MT?

The authors of this article, by presenting that study through the prism of recent events (Jennings, 2017), aim to provide (a) the most accurate information available, but most importantly (b) a forum for the exchange of information in regards to the future of our profession and MT training.

\section{Method}

\subsection{Experimental Approach to the Problem}

This study followed an observational and cross-sectional model. Data were collected on a quantitative instrument (i.e., questionnaire) and on a qualitative instrument (i.e., interview) to see if these two data types revealed similar results, but from different perspectives. A fixed mixed method design was used, since the use of both quantitative and qualitative methods were scheduled at the beginning of the process and were carried out as such.

The research problem suited for mixed methods because one data source would be insufficient and the authors were looking for triangulation (e.g., greater validity), offset, completeness, complementarity, and initiation. The two strands were kept independent until the interpretation of the results. Concerning the timing of the collection of the data (see Figure 1), concurrent time was implemented (i.e., a single phase of implementation). Furthermore, this is a convergent design (i.e., "QUAN + QUAL"), not only because both strands were implemented at the same time, but also because both had the same emphasis (i.e., equal status) and their separate results were converged. In fact, the point of interface was at the interpretation of the results.

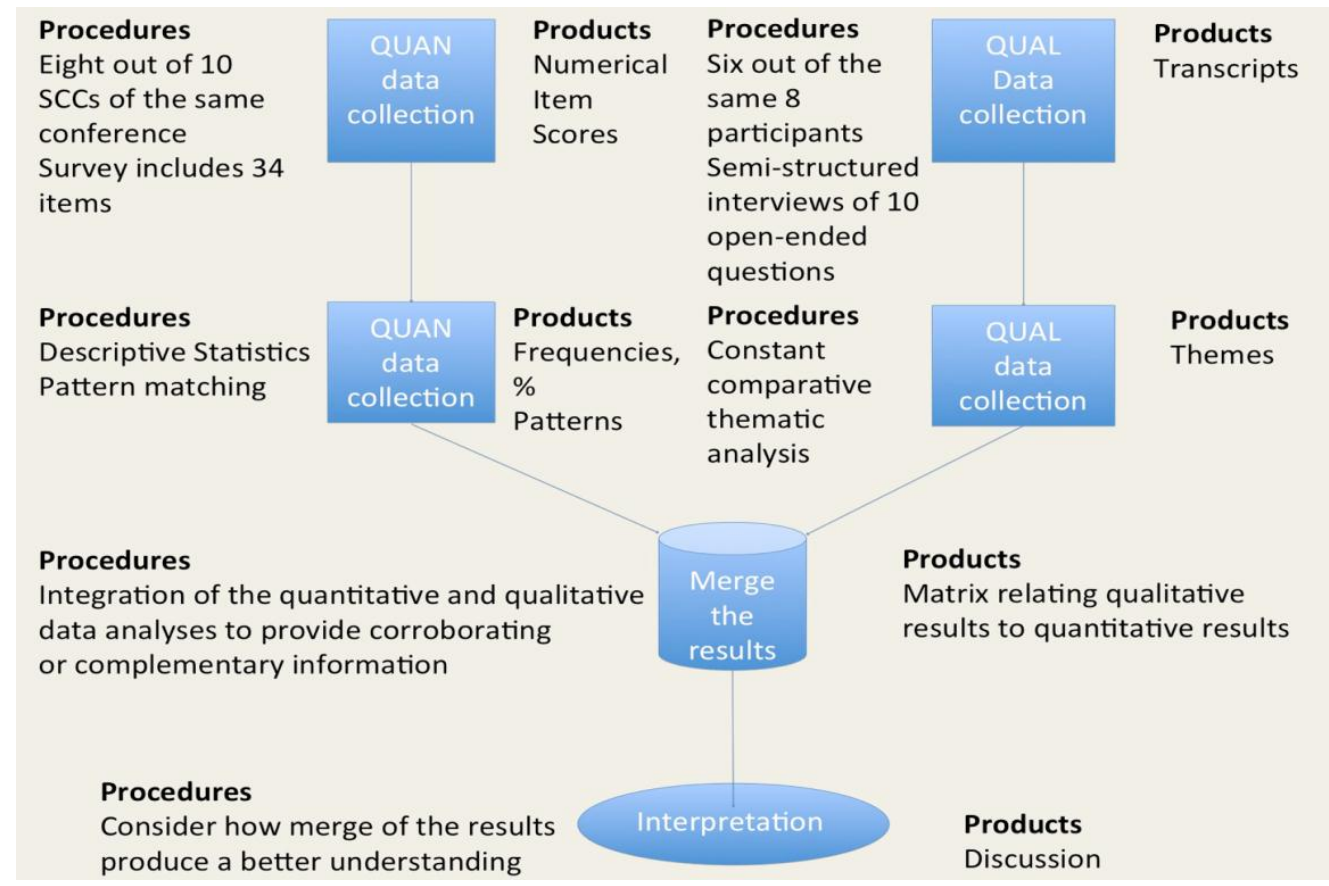

Figure 1. Diagram of the procedures for this convergent-design study 


\subsection{Materials}

\subsubsection{Questionnaire}

The Stronger Than Average Mentality (S.T.A.M.) questionnaire is a 34-item instrument with two rank-order questions (i.e., items 19 and 27), two matrix-table questions (i.e., items 13 and 14), one short-answer question (i.e., item 17), and 29 multiple-choice questions (i.e., 28 Likert-type and one yes-or-no). Seven areas of interest are covered: (a) Do Strength and Conditioning Coaches (SCC) know what mental toughness is? (b) What's their opinon about the value of mental toughness? (c) Are they implenting any kind of mental toughness training? (d) Do they know how to measure mental toughness? (e) Can they indentify and rank the key issues in this area? (f) Do they think that there are gender differences when it comes to implementing mental toughness training? (g) Would they be interested in learning more about mental toughness? and (h) Do they think that there are any differences in the responsibilities to develop mental toughness when compared to baskeball coaches? The demographic items were designed to collect information about the gender, job title, academic background, years of experience as a SCC, years of experience as a SCC for female student-athletes, and years of experience as a SCC for collegiate female basketball players of the participants (see Appendix).

The S.T.A.M. questionnaire was inspired by a description of the questionnaire developed and provided by Weinberg, Butt, and Culp (2011) and the definition and the attributes of the term MT is replicated from Jones et al. $(2002,2007)$. Actually, in the beginning of the questionnaire, Jones' definition of MT was stated in order to increase the construct validity of this research.

Jones' definition and framework were used in preference to others because -besides being popular-it (a) specifically states that MT can be developed and (b) includes non-sport contexts, too (e.g., lifestyle, post-competition). The latter relates to the potential transferability of the construct. Lastly, when compared to others during pilot testing, such as Clough, Earle, and Sewell (2002) and Gucciardi, Gordon, and Dimmock (2008), coaches found this particular definition easier to grasp.

Four professionals with relevant experience in collegiate athletics agreed to fill out the questionnaire and provide feedback in regards to content-related validity and face validity. In more detail, the instrument's appearance was assessed. Furthermore, the test items were checked based on the research questions and they were evaluated whether they sample the particular performance domain. The experts reported that the items adequately collect information about the perceptions of SCCs in regards to MT in Sport. Besides some minor grammatical and syntactical errors, they did not report any major issues in regards to the content, the level of complexity, the item format, or the response format of the items. However, based on their feedback, one alteration was made: in items 13 and 14 the word "practice" was substituted with "session".

After the S.T.A.M. was administered, the item clusters for which reliability could be estimated were: (a) Importance, (b) Gender Differences, (c) Development, (d) Applications, and (e) SCCs versus HCs. Reliability was estimated using Guttman's $\lambda_{2}$, which is arguably a more trustworthy estimate of reliability than coefficient $\alpha$ (Sijtsma, 2009). The $\lambda_{2}$ estimates for the item clusters mentioned above were .61, .91, .92, .73, and .69, respectively.

\subsubsection{Interview}

A semi-structured interview was completed that focused on 10 open-ended questions (see Appendix). The areas of interest were the same as above. For instance, the coaches were asked to state their opinion about the value or MT and also, if they are implementing any kind of MT training. Jones' definition was again used in the beginning of each session.

\subsection{Participants}

National Collegiate Athletic Association (NCAA) Division I strength and conditioning coaches for collegiate women's basketball were recruited via email. The sample was a criterion-based purposive sample as all participants were members of the same Power 5 conference, located in Central, Mid-West, and Mid-Atlantic America (see Table 1 for demographics). There was no randomized recruitment.

Out of the ten SSCs in this conference, eight responded to the questionnaire and six -out of these eight- were interviewed via phone or in person. In regards to the questionnaire, recruitment discontinued after three attempts via email, while for the interview after two attempts. 
Table 1. Descriptive Statistics $(n=8)$

\begin{tabular}{lll}
\hline Variables & Count & $\%$ \\
\hline Gender & & \\
Males & 6 & 75.0 \\
Female & 2 & 25.0 \\
Academic Background & & \\
Bachelor's & 4 & 50.0 \\
Master's & 4 & 50.0 \\
CSCS & 6 & 75.0 \\
USAW & & 75.0 \\
SCCC & 6 & 62.5 \\
Experience as SCC & 5 & \\
2-5 years & & 12.5 \\
6-10 years & 1 & 50.0 \\
11-15 years & 4 & 25.0 \\
16-20 years & 2 & 12.5 \\
Experience as SCC for female student-athletes & 1 & \\
2-5 years & & \\
6-10 years & 1 & 12.5 \\
11-15 years & 1 & 50.0 \\
16-20 years & 1 & 25.0 \\
Experience as SCC for female basketball student-athletes & 12.5 \\
2-5 years & 1 & 12.5 \\
6-10 years & & \\
11-15 years & 50.0 \\
16-20 years & 1 & 12.5 \\
\hline
\end{tabular}

Note. ${ }^{a}$ Certified Strength and Conditioning Specialist. ${ }^{\mathrm{b}}$ USA Weightlifting. ${ }^{\mathrm{c}}$ Strength and Conditioning Coach Certified

\subsection{Procedures}

\subsubsection{Questionnaire}

After the Institutional Review Board (IRB) approval, the questionnaire was uploaded on Qualtrics (www.qualtrics.com). The participants were contacted electronically receiving information about why they were chosen to participate in this project, the rationale of the study, and the link along with the necessary password. The participants were then able to go online and complete the questionnaire. Based on response rate, a second and a third email were sent reminding the subjects to complete the questionnaire. These follow-up emails also contained the link and the password.

\subsubsection{Interview}

The participants were initially contacted via email approximately 2 weeks prior to them visiting the home campus of the authors to play against a local basketball team. They were asked: (a) to reveal their intentions about participating or not in this part of the project and (b) if they were going to travel with their team for the upcoming game. The same email was sent to them one week prior to the game, if they had not responded to the first email. In case they agreed to participate, one more email was sent as a reminder three days prior to the interview, including the consent form. 
A face-to-face interview occurred for those SCCs that traveled with the team. At the beginning of each interview, the participants were asked to allow the researchers to record the interview, which they all agreed. Three -out of the 6participants (50\%) were interviewed face-to-face with two happening at the campus basketball arena and one at a local hotel, where the team stayed.

Following the flexible model of responsive interview (Rubin \& Rubin, 2012), a phone interview was scheduled for the three SCCs that were unable to travel with their team. Consistent with the face-to-face interviews, the phone participants were asked to allow the researchers to record the interview, which they all agreed. For the three phone interviews, the researcher was located in an academic building on the university campus and the SCCs in their offices of their institutions.

\subsection{Statistical Analyses}

Capturing the descriptive information about the sample was the goal of analysis of the quantitative data. Therefore, first, we generated descriptive statistics for each of the variables of interest. Since these were all categorical variables, we generated frequencies and percentages. Second, we examined the data from the questionnaires concerning the seven areas of interest. These seven areas provided lenses through which data was viewed in a relational structure. In the Likert-type questions, we identified "Agree" and "Strongly Agree" answers as positive and "Disagree" and "Strongly Disagree" as negative.

Data reduction was the goal of analysis of the qualitative data. Through constant comparative thematic analysis, we examined the data from the transcripts of the interviews concerning the seven areas of interest too and coding was based on these seven areas. Two raters examined the data and inter-rater agreement percentage reached $92 \%$.

Last, we integrated the results from the two strands looking for corroborating or complementary information. Two raters were used to merge the qualitative and qualitative data analyses (see Table 2) and their inter-rater agreement was $90 \%$. In cases of conflict between the results of the quantitative and qualitative strands, analytic induction was run.

\section{Results}

Results are presented in Table 2. While there was no agreement whether MT can be developed in student-athletes or about its key attributes, all coaches believed MT is of value. Further, none of the participants reported being aware of or using an instrument to measure MT. Conclusions are that MT is a widely-used but relatively unclear construct. The high level of difficulty to access this particular population of collegiate coaches (due to their elite status), should be taken into consideration during the interpretation of the results and their practical inferences. Below, the results are broken down by interest area with emphasis on the qualitative strand due to its nature.

\subsection{Definitions of MT}

In the beginning of both the questionnaire and the interview, the participants were introduced to Jones' definition of MT in order to support the construct validity of this study (Note 1). During the questionnaires and the interviews, -although the majority claimed that they know what MT is- when participants were asked to rank the attributes that Jones used to explain and describe MT, there was high variability. At the same time, during the interviews, 83\% described or actually used the phrase "overcoming adversity" as well as the term consistency in their definition of MT.

\subsection{Importance of $M T$}

Based on the quantitative and qualitative evidence, there was consensus in regards to the importance of MT. One coach mentioned: "Although it's so hard for me to define MT, it is very valuable. It won't make a Division III team beat UConn, but MT can push you over the edge." While another coach stated that "MT gives you an extra edge." A third coach added, after supporting that MT is extremely valuable: "You know... The game is won between the ears."

\subsection{Development of $M T$}

From the questionnaires, it was observed that $87.5 \%$ of the coaches believe that MT can be developed, although $37.5 \%$ of them believe that trying to develop MT at the age of 18 to 22 may be a waste of time. The results of the interviews showed that although all coaches, believe that, as Jones claims, MT may be developed (e.g., "I think MT can be developed, because we are dealing with high-caliber athletes. Especially, in our conference, they are the best of the best. I would definitely say it is a developed trait"), $50 \%$ of the respondents were unsure that MT can be developed in student-athletes. One coach stated, "You have a 4-year window, while they have been in their house for 18. So, I think you can help it, but you cannot change it a whole lot. We are responsible for $10 \%$ maximum. It's like shooting free throws. You may tweak it a little bit, but you cannot change the overall mechanics here." Another coach 
added, "I'm saying you can develop it, but, by the time you get to the collegiate age, I think your window for improvement is pretty narrow at that point." It was interesting that two coaches used the example of the U.S. Navy Seals to prove a completely opposite point. One interviewee argued that since the majority of the applicants fail the first week of the training that proves that it is too late to develop MT during this age. The other coach claimed that the fact that the Navy Seals are adults during training, and finish mentally tougher than before, proves that MT can be trained after 18 years of age.

\subsection{Gender Differences}

The data from the questionnaires revealed that the majority of the SCCs did not see any gender differences in MT training. The evidence from the interviews disclosed that all the coaches did not believe that one gender is tougher than the other ("When I coach women, I don't see gender, I see athletes.", "Genders are different, but not that one is tougher than the other, and I don't think they [men] are necessarily more mentally tough. I think they can appear to be more mentally tough"), but it depends on the individual ("Yes, you may need different individual training, but not as a team"). At the same time, two out of six (33\%) of the coaches thought that there are some slight gender differences (e.g., menstrual cycle, women are more emotional) when it comes to implementing MT training.

\subsection{SCCs vs. Basketball Coaches}

Most of the questionnaire participants considered the $\mathrm{HC} / \mathrm{BC}$ to be more responsible for any kind of MT training. The majority of the interviewees recognized that the $\mathrm{BCs}$ are in charge: "The $\mathrm{HC}$ is more responsible because it has to be more specific," "It doesn't transfer enough to the court from what we are doing them. The coaches must be extremely involved," "SCCs train more general MT, BCs train more situational-specific MT," "I think the practice environment pushes everything," and "My role and responsibility is to prepare them for the MT training that she (the coach) will put them through with a basketball in their hands. Because if they can't push through my stuff, they can't push through her stuff." All six coaches pointed out the need of having the same goals with the BCs. One SCC commented "Everything comes from the BCs. It needs to be intentional. They have to be supportive" and "There has to be a synergistic relationship as opposed to antagonistic," while another added, "I have to be on the same page with the BC, in sync." One SCC gave examples of how it is situational and finished his answer by saying, "It depends on the team, on the role of the coach. Does the coach have a disciplinary role or me?" One participant was more specific by stating that "Seventy percent comes from the coach." At the same time, one SCC complained passionately about the ignorance of the BCs, "They just throw out the term mental toughness for you. They want you to train it. They don't tell you what their opinion of it is. You ask them. They have no idea! Their idea of MT is going out and throwing up... on the stadium."

\subsection{Application}

The results from the questionnaires revealed that $87.5 \%$ of the participants believed that they knew how to develop MT and implement MT training, but did not know how to measure it. Interestingly, none of the participants incorporated MT training in season, although $87.5 \%$ would like to be able to do it. After analyzing the transcripts of the interviews, it was clear that $100 \%$ of the participants believed they implement MT in their training. Specifically, the participants reported that they may have some "special" training scheduled (e.g., post-season challenge, early morning workouts, "work capacity" days), but it remains very hard for them to separate it from their physical training: "It's hard to separate MT from the rest of the training," "I put MT in my physical training, but not separately," and "You don't necessarily have to dedicated 30 minutes of the workout for MT." At the same time, most of the SCCs (5 out of 6) mentioned that everything about their job includes MT training, because most often the basketball players like playing basketball, not lifting weights, nor running: "They only know basketball," "They don't give them scholarships to be weight-lifters," "In strength and conditioning, everything they do with us is pretty uncomfortable," "Most of the weight training is about MT," and "I am trying to incorporate some psychological challenges in my physical training, but physical training has MT in it anyway". Lastly, only 1 out of the 6 teams actually brings a specialist to train MT once or twice per year. None of the coaches reported any kind of purely psychological training to develop MT (e.g., coping strategies, relaxation techniques, imagery), but always as part of their physiological training.

Concerning measurement, although they comprehended its value ('If you can't measure it, I don't know how you prove it"), none of the coaches showed any knowledge about the instruments that already exist ("There is no objective test that I do"). Instead, they used visual observation in order to determine if their athletes become mentally tougher: "No instrument, just body language," "I'm a very visual coach. I read body language very well," "It is subjective," and "Body language is huge". 


\subsection{Level of Interest}

There was general consensus in both the questionnaire and interview that all SCCs would like to know more about MT. In fact, 3 out of 6 coaches became more specific and stated that are looking -without significant success thoughfor research that has to do with MT training and read books or scientific articles. One coach noted the fact that there are not enough articles in the coaching journals.

Table 2. Comparison of Information from Questionnaire and Interview Data: 7 themes

\begin{tabular}{|c|c|c|}
\hline Theme & $\begin{array}{l}\text { Questionnaire } \\
\text { (QUAN results) }\end{array}$ & $\begin{array}{c}\text { Interview } \\
\text { (QUAL results) }\end{array}$ \\
\hline $\begin{array}{l}\text { 1. Definition } \\
\text { of MT }\end{array}$ & $\begin{array}{l}\text { 87.5\% supported that they know what MT is } \\
87.5 \% \text { ranked attitude/mindset as the most } \\
\text { important attribute of MT } \\
50 \% \text { ranked "Having an unshakable self-belief in your ability to achieve } \\
\text { your competition goals. " as \#1; } 62.5 \% \text { ranked "Remaining fully-focused in } \\
\text { the face of personal life distraction." as \#4; and } 62.5 \% \text { ranked "Switching a } \\
\text { sport focus on and off as required" as \#5. }\end{array}$ & $\begin{array}{l}75 \% \text { included or described } \\
\text { "overcoming adversity" in } \\
\text { their definition of MT } \\
\text { High variability when } \\
\text { ranking the key issues in this } \\
\text { area. }\end{array}$ \\
\hline $\begin{array}{l}\text { 2. Is MT } \\
\text { important? }\end{array}$ & $\begin{array}{l}100 \% \text { SCCs should be mentally tough } \\
87.5 \% \text { believe MT is not worthless } \\
100 \% \text { believe that MT provides the athlete with a psychological advantage } \\
62.5 \% \text { believe that MT scores should be used during recruitment } \\
100 \% \text { believe that it would be useful to have a reliable instrument for MT. }\end{array}$ & $\begin{array}{l}100 \% \text { believe that MT is } \\
\text { valuable. }\end{array}$ \\
\hline $\begin{array}{l}\text { 3. Can MT be } \\
\text { developed? }\end{array}$ & $\begin{array}{l}87.5 \% \text { believe that MT can be developed } \\
37.5 \% \text { believe that trying to develop MT at the age between } 18 \text { and } 22 \text { is a } \\
\text { waste of time. }\end{array}$ & $\begin{array}{l}50 \% \text { believe that MT can be } \\
\text { developed. }\end{array}$ \\
\hline $\begin{array}{l}\text { 4. Are there } \\
\text { any gender } \\
\text { differences? }\end{array}$ & $\begin{array}{l}25 \% \text { believe that men are mentally tougher than women } \\
25 \% \text { believe that female collegiate players need more training in MT than } \\
\text { males } \\
12.5 \% \text { believe that MT is more difficult to develop in women than men } \\
12.5 \% \text { believe that mentally tough athletes make more of a difference in } \\
\text { women's sports than in men's sports. }\end{array}$ & $\begin{array}{l}36 \% \text { believe that there are } \\
\text { gender differences when it } \\
\text { comes to implementing MT } \\
\text { training. }\end{array}$ \\
\hline $\begin{array}{l}\text { 5. SCCs vs. } \\
\text { HCs. }\end{array}$ & 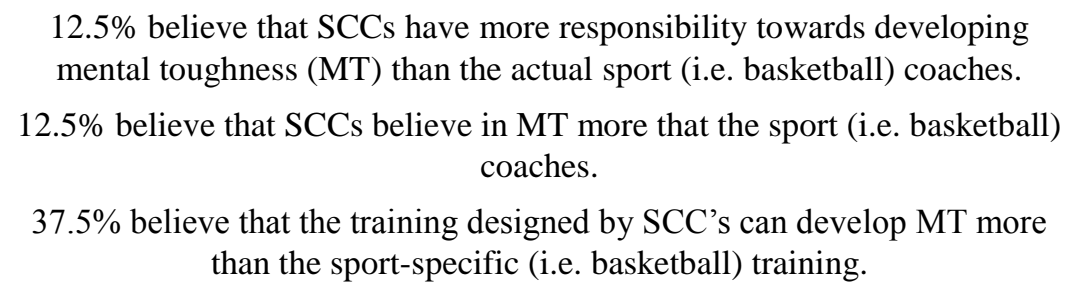 & $\begin{array}{l}83 \% \text { believe that the } \mathrm{HC} \text { has } \\
\text { more responsibility towards } \\
\text { developing MT. }\end{array}$ \\
\hline $\begin{array}{l}\text { 6. Application } \\
\text { of MT }\end{array}$ & $\begin{array}{l}\text { In-season: } 0 \% \text { incorporate MT training in season; } 87.5 \% \text { would like to be } \\
\text { able to }\end{array}$ & $\begin{array}{l}100 \% \text { implement } \mathrm{MT} \text { in } \\
\text { their training }\end{array}$ \\
\hline training & $\begin{array}{l}87.5 \% \text { believe that know how to develop MT and implements MT training } \\
\text { while } 87 . \% \text { do not know how to measure it } \\
\begin{array}{l}12.5 \% \text { believe that MT can be practiced by a specialized professional (e.g., } \\
\text { sport psychologist) only. }\end{array}\end{array}$ & $\begin{array}{l}0 \% \text { uses any instrument to } \\
\text { measure it. }\end{array}$ \\
\hline $\begin{array}{l}\text { 7. Level } \\
\text { of interest }\end{array}$ & $100 \%$ would like to know more about MT. & $\begin{array}{l}100 \% \text { are interested in } \\
\text { knowing more about MT. }\end{array}$ \\
\hline
\end{tabular}




\section{Discussion}

Research of MT in collegiate strength and conditioning is in its relative infancy. However, the inferences of the results of the study above combined with evidence from the literature will have an impact on the researchers, SSCs, and organizations that are in close relationship with SCCs, such as the National Strength and Conditioning Association (NSCA) and the Collegiate Strength and Conditioning Coaches association (CSCCa) -especially in light of the recent Pac-12 event.

In more detail, the findings confirmed conclusions of previous research, which indicated that, although MT is reported to be widely used, at the same time, it is still a very unclear term (Dohme et al., 2017; Gucciardi et al., 2016). The fact that SCCs characterized MT as a high-valued concept justifies the recent increase in research and also the frequent use of the term from athletes, coaches, fans, and commentators. At the same time, allocation of more resources towards studying MT may also be justified since SCCs appeared to be very interested in learning more about it.

However, MT has been found to have an association with years of experience and chronological age (Connaughton, Hanton, \& Jones, 2010; Nicholls et al., 2009). This discrepancy seems to support that more research is necessary to assess that relationship. A definitive answer will have a significant impact on the training of MT. For instance, if MT can be developed during college, more resources should be allocated towards this kind of training. Another issue that needs clarification through more research and will also affect the amount of resources allocated is gender differences. More particularly, although the majority of SSCs did not report genders differences, there is preliminary evidence that males score significantly higher than females on MT instruments (e.g., Crust \& Keegan, 2010). Lastly, in this study, there was a distinct emphasis on physical strategies, although positive correlations between mental toughness and use of psychological strategies (e.g., imagery) have been reported (e.g., Crust \& Azadi, 2010).

Considering the limitations and delimitations of this study (e.g., very low number of participants), there are no issues with external validity or transferability, since there is no intention to generalize findings across populations, settings, or time. The findings reflect only the beliefs of the SCCs for women's basketball of a specific NCAA conference in regards to MT. However, although the findings may not be statistically generalizable, they are generalizable in method (theoretically). Obtaining unequal samples sizes for the qualitative and qualitative data collection is a potential validity threat. There is no statistical conclusion validity issue since the response rate was very high with $80 \%$ and $60 \%$ of the coaches participating in the questionnaire and the interview parts respectively. In addition, the completion rate was $100 \%$ (i.e., no missing data).

Nevertheless, there are several issues when it comes to internal validity or credibility. First of all, they are self-reported data, which means that they may be superficial or misleading. For example, some coaches may be reluctant to reveal their techniques assuming that there is a high risk of a leak of their "secrets" to a representative of an opponent (i.e., the researcher). In addition, there is a significant instrumentation threat: although the questionnaire was piloted, there isn't enough data to prove that its scores are reliable and/or their inferences are valid. Although there is no or low threat when it comes to history (never examined before), attrition (no drop-outs), and selection bias (all coaches were selected), there is social interaction threat. In more detail, the researchers did not know the identity of the coaches who completed the online questionnaire. However, most of the coaches know each other and may have communicated prior or even during the completion of the questionnaire or before getting interviewed. Lastly, the inclusion of a specific definition of MT prior to the interviews/questionnaire may have resulted to confounded data. However, due to the fact that the literature review concluded that people are vague about the concept, the authors chose to enhance the construct validity of the study instead.

More research is definitely needed about the opinions of SCCs. Future research should possibly use a different definition than Jones', not include any definition at all and perhaps proceed with a more grounded theory approach, and recruit SCCs from other sports and different environments (e.g., conference, level, country). Definition, measurement, and implementation are issues that should be addressed in the future research efforts.

\subsection{Practical Implications}

Incidents, like the one in January 2017, have happened before (e.g., Associated Press, 2014). Did our professional community learn from those though? If so, why do they keep happening? Although a lot of different variables can lead to events like that (e.g., questionnable certification process; Solomon \& Dodd, 2017), it seems that it is time we left anecdotally-based protocols behind us and moved towards empirically-based practices. It seems that it is time -through future research and deliberate effort in personal, institutional, and organizational level- strength and conditioning professionals provided answers to the following practical questions: 
- How do we, SCCs, train something that we still cannot clearly conceptualize?

- Without being able to define MT and in our effort to develop the "toughest" student-athletes, do we comprehend the dynamic relationship between MT and mental health (Gearity \& Moore, 2017; Gucciardi, Hanton, \& Fleming, 2017; Velasco, 2017)?

- Even if $40 \%$ of the participants think that it may be too late to develop MT in student-athletes, why does the majority still practice it?

- Even if we implement MT training in that age range, how much can MT be developed? In other words, in our limited by-NCAA-rules time, is it worth it?

- How do we know our protocols have a positive impact on our athletes, when none of the participants reported to use an inventory to measure the effectiveness of their interventions? Is "seeing" it enough?

- Why are our interventions primarily physical? Don't we have the appropriate knowledge/training? Are we afraid of malpractice? Should organizations, such as the NSCA and CSCCa, include evidence-based MT training in the study materials for their certification exams?

- Why don't we implement more MT training protocols, although we want to? Is it because of time restrictions? Is it because of lack of support from the HCs? and

- SCCs spend more countable hours with the athletes throughout the year than the HCs (University of Notre Dame, 2015). Nevertheless, since we tended to agree that the HC is more responsible for this kind of training, should MT be trained mostly under the supervision of the HC and not the SCC?

\section{References}

Associated Press. (2014). William Lowe files suit vs. Iowa. Retrieved from http://www.espn.com/college-football/story/_id/10588363/william-lowe-files-suit-rhabdo-injuries

Clough, P., Earle, K., \& Sewell, D. (2002). Mental toughness: The concept and its measurement. In I. M. Cockerill (Ed.), Solutions in sport psychology (pp. 32-43). Longon, England: Thompson.

Connaughton, D., Hanton, S., \& Jones, G. (2010). The development and maintenance of mental toughness in the world's best performers. Sport Psychologist, 24(2), 168-193. Retrieved from http://www.scopus.com/inward/record.url?eid=2-s2.0-77955892221\&partnerID=40\&md5=2d8c059529d2f9958 d7f43eba6c66c71

Crust, L., \& Azadi, K. (2010). Mental toughness and athletes' use of psychological strategies. European Journal of Sport Science, 10(1), 43-51. https://doi.org/10.1080/17461390903049972

Crust, L., \& Keegan, R. (2010). Mental toughness and attitudes to risk-taking. Personality and Individual Differences, 49(3), 164-168. https://doi.org/10.1016/J.Paid.2010.03.026

Dohme, L.-C., Backhouse, S., Piggott, D., \& Morgan, G. (2017). Categorising and defining popular psychological terms used within the youth athlete talent development literature: a systematic review. International Review of Sport and Exercise Psychology, 10(1), 134-163.

Gearity, B., \& Moore, E. W. G. (2017). National Strength and Conditioning Association's Endorsement of the National Collegiate Athletic Association Sport Science Institute's "Mental Health Best Practices: Inter-Association Consensus Document: Best Practices for Understanding and Supporting Student-Athlete Mental Wellness". Strength \& Conditioning Journal, 39(4), 1-3.

Gibson, A. (1998). Mental toughness. New York, NY: Vantage Press.

Gucciardi, D. F., \& Gordon, S. (2009). Development and preliminary validation of the Cricket Mental Toughness Inventory (CMTI). Journal of Sports Sciences, 27(12), 1293-1310. https://doi.org/10.1080/02640410903242306

Gucciardi, D. F., Gordon, S., \& Dimmock, J. A. (2008). Towards an understanding of mental toughness in Australian football. Journal of Applied Sport Psychology, 20(3), 261-281. https://doi.org/10.1080/10413200801998556

Gucciardi, D. F., Gordon, S., \& Dimmock, J. A. (2009). Evaluation of a mental toughness training program for youth-aged Australian footballers: I. A quantitative analysis. Journal of Applied Sport Psychology, 21(3), 307-323. https://doi.org/10.1080/10413200903026066 
Gucciardi, D. F., Gordon, S., Dimmock, J. A., \& Mallett, C. J. (2009). Understanding the coach's role in the development of mental toughness: perspectives of elite Australian football coaches. Journal of Sports Sciences, 27(13), 1483-1496. https://doi.org/10.1080/02640410903150475

Gucciardi, D. F., Hanton, S., \& Fleming, S. (2017). Are mental toughness and mental health contradictory concepts in elite sport? A narrative review of theory and evidence. Journal of Science and Medicine in Sport, 20(3), 307-311.

Gucciardi, D. F., Zhang, C.-Q., Ponnusamy, V., Si, G., \& Stenling, A. (2016). Cross-cultural invariance of the mental toughness inventory among Australian, Chinese, and Malaysian athletes: a bayesian estimation approach. Journal of Sport and Exercise Psychology, 38(2), 187-202.

Jennings, C. (2017). Report: 3 Oregon football players hospitalized after 'grueling' workouts. Retrieved from http://www.espn.com/college-football/story/_/id/18491292/three-oregon-ducks-football-players-hospitalized-str ength-conditioning-workouts

Jones, G., Hanton, S., \& Connaughton, D. (2002). What is this thing called mental toughness? An investigation of elite sport performers. Journal of Applied Sport Psychology, 14(3), 205-218. https://doi.org/10.1080/10413200290103509

Jones, G., Hanton, S., \& Connaughton, D. (2007). A framework of mental toughness in the world's best performers. Sport Psychologist, 21(2), 243-264. Retrieved from <Go to ISI>://WOS:000247452000007

Loehr, J. E. (1986). Mental toughness training for sports: Achieving athletic excellence. Lexington, MA: Penguin Books.

Mack, M. G., \& Ragan, B. G. (2008). Development of the mental, emotional, and bodily toughness inventory in collegiate athletes and nonathletes. Journal of Athletic Training, 43(2), 125-132. https://doi.org/10.4085/1062-6050-43.2.125

Nicholls, A. R., Polman, R. C. J., Levy, A. R., \& Backhouse, S. H. (2009). Mental toughness in sport: Achievement level, gender, age, experience, and sport type differences. Personality and Individual Differences, 47(1), 73-75. https://doi.org/10.1016/J.Paid.2009.02.006

Oklahoma State University. (2015). Strength and Conditioning. Retrieved from http://www.okstate.com/sports/2015/3/17/GEN_2014010168.aspx

Oklahoma University. (2007). Oklahoma Men's Basketball Media Guide 2007-08. Retrieved from http://www.soonersports.com/fls/31000/old_site/pdf/m-baskb1/Recruiting.pdf?DB_OEM_ID=31000

Radcliffe, J. N., Comfort, P., \& Fawcett, T. (2013). The perception of psychology and the frequency of psychological strategies used by strength and conditioning practitioners. Journal of Strength \& Conditioning Research, 27(4), 1136-1146. https://doi.org/10.1519/JSC.0b013e3182606ddc

Rubin, H. J., \& Rubin, I. S. (2012). Qualitative interviewing: The art of hearing data. Thousand Oaks, CA: Sage.

Seligman, M. E., \& Csikszentmihalyi, M. (2014). Positive psychology: An introduction. Flow and the foundations of positive psychology (pp. 279-298). New York, NY: Springer.

Sheard, M., Golby, J., \& van Wersch, A. (2009). Progress Toward Construct Validation of the Sports Mental Toughness Questionnaire (SMTQ). European Journal of Psychological Assessment, 25(3), 186-193. https://doi.org/10.1027/1015-5759.25.3.186

Sijtsma, K. (2009). On the use, the misuse, and the very limited usefulness of cronbach's alpha. Psychometrika, 74(1), 107-120. https://doi.org/10.1007/s11336-008-9101-0

Solomon, J., \& Dodd, D. (2017). The unregulated world of strength coaches and college football's killing season. Retrieved

from https://www.cbssports.com/college-football/news/the-unregulated-world-of-strength-coaches-and-college-footb alls-killing-season/

Stamatis, A., Robinson, E. L., \& Morgan, G. B. (2017). Mental Toughness in Strength and Conditioning Training: Is it really necessary? Perspectives of elite NCAA Strength and Conditioning coaches. Paper presented at the International Journal of Exercise Science: Conference Proceedings.

University of Notre Dame. (2015). Countable Hours. Retrieved from http://www3.nd.edu/ ncaacomp/countable_hours.shtml 
Velasco, H. (2017). Few student-athletes with mental illness seek help. Retrieved from http://college.usatoday.com/2017/07/21/few-student-athletes-with-mental-illness-seek-help/

Weinberg, R., Butt, J., \& Culp, B. (2011). Coaches' views of mental toughness and how it is built. International Journal of Sport and Exercise Psychology, 9(2), 156-172.

West Virginia University. (2015). 2015 West Virginia University Volleyball Guide. Retrieved from https://issuu.com/wvusportspub/docs/2015_west_virginia_university_volle

Note

Note 1. "Having the natural or developed psychological edge that enables you to: generally, cope better than your opponents with the many demands (competition, training, lifestyle) that sport places on a performer; specifically, be more consistent and better than your opponents in remaining determined, focused, confident, and in control under pressure." (Jones et al., 2007 p. 209)

\section{Appendix}

\section{Survey of NCAA Division 1 Strength \& Conditioning Coaches}

\section{Directions:}

This is the first of the two parts of a project investigating Big12 women's basketball strength and conditioning coaches' (SCC) opinions about mental toughness.

There are not right or wrong answers, so please respond as honestly as possible. It should take you less than 10 minutes to complete.

Use the following definition of mental toughness (MT) to answer the questions.

"Mental toughness is having the natural or developed psychological edge that enables you to:

- Generally, cope better than your opponents with the many demands (e.g., competition, training, lifestyle) that are placed on you as a performer.

- Specifically, to be more consistent and better than your opponents in remaining determined, focused, confident, resilient, and in control under pressure."

1. How important do you think it is for a strength and conditioning coach (SCC) to be mentally tough? (Circle One)

Very Somewhat Neutral Somewhat Very

Important Important Unimportant Unimportant

2. Men in general are mentally tougher than women. (Circle One)

Strongly Agree Agree Disagree Strongly Disagree

3. SCCs have more responsibility towards developing mental toughness (MT) than the actual sport (i.e. basketball) coaches. (Circle One)

Strongly Agree Agree Disagree Strongly Disagree

\section{I believe MT training is worthless. (Circle One)}

Strongly Agree Agree Disagree Strongly Disagree 
5. I don't know how to develop MT. (Circle One)

Strongly Agree Agree Disagree Strongly Disagree

6. Female collegiate players need more training in MT than males. (Circle One)

Strongly Agree Agree Disagree Strongly Disagree

7. I believe MT can be developed in athletes. (Circle One)

Strongly Agree Agree Disagree Strongly Disagree

8. MT provides the athlete a psychological advantage over opponents. (Circle One)

Strongly Agree Agree Disagree Strongly Disagree

9. SCCs believe in MT more that the sport (i.e. basketball) coaches. (Circle One)

Strongly Agree Agree Disagree Strongly Disagree

10. I believe that the training designed by SCC's can develop MT more than the sport-specific (i.e. basketball) training. (Circle One)

Strongly Agree Agree Disagree Strongly Disagree

11. I believe that MT is more difficult to develop in women than in men. (Circle One)

Strongly Agree Agree Disagree Strongly Disagree

12. MT measurements/scores should be used while recruiting? (Circle One)

Strongly Agree Agree Disagree Strongly Disagree

13. If you had the freedom to choose, which would be the best time of the year to practice MT training? Also, in the period(s) you choose, circle the number of sessions per week (Circle one per row). *(Note: Circle all of the zero's -0- if you don't believe MT can be taught)

\begin{tabular}{llccc}
\hline TIME OF THE YEAR & & \multicolumn{2}{c}{ SESSIONS PER WEEK } & $6-7$ \\
\hline All-year round & 0 & $1-2$ & $3-5$ & $6-7$ \\
\hline Postseason & 0 & $1-2$ & $3-5$ & $6-7$ \\
\hline Offseason & 0 & $1-2$ & $3-5$ & $6-7$ \\
\hline Preseason & 0 & $1-2$ & $3-5$ & $6-7$ \\
\hline Inseason & 0 & $1-2$ & $3-5$ & 6 \\
\hline
\end{tabular}


14. When do you actually incorporate MT training? Also, in the period(s) you choose, circle the number of sessions per week (Circle one per row). *(Note: Circle all of the zero's -0- if you don't incorporate MT)

\begin{tabular}{llccr}
\hline TIME OF THE YEAR & \multicolumn{3}{c}{ SESSIONS PER WEEK } \\
\hline All-year round & 0 & $1-2$ & $3-5$ & $6-7$ \\
\hline Postseason & & & $6-7$ \\
\hline Offseason & 0 & $1-2$ & $3-5$ & $6-7$ \\
\hline Preseason & 0 & $1-2$ & $3-5$ & $6-7$ \\
\hline Inseason & 0 & $1-2$ & $3-5$ & $6-7$ \\
\hline
\end{tabular}

15. How useful would it be to have a reliable instrument that could measure MT? (Circle One)

$\begin{array}{lcrl}\text { Very } & \text { Somewhat } & \text { Neutral } & \text { Somewhat Very } \\ \text { Useful } & \text { Useful } & & \text { Useless Useless }\end{array}$

16. I don't know how to measure MT. (Circle One)

Strongly Agree Agree Disagree Strongly Disagree

17. To the best of your knowledge, in the past year, what percentage of D1 women's basketball programs included MT development techniques into their training? $\%$

18. I believe that the mentally toughest athletes during practice are also the toughest ones during competition. (Circle One)

Strongly Agree Agree Disagree $\quad$ Strongly Disagree

19. Rank in order the following components of MT from 1 to 5 ( 1 being the most important).

_ Having an unshakable self-belief in your ability to achieve your competition goals.

_ Bouncing back from performance set-backs as a result of increased determination to succeed.

_ Remaining fully-focused in the face of personal life distractions.

_ Pushing back the boundaries of physical and emotional pain, while still maintaining technique and effort under distress (in training and competition).

Switching a sport focus on and off as required.

20. A mental tough athlete can cope better with unique demands that arise from the lifestyle associated with being an elite athlete. (Circle One)

Strongly Agree Agree Disagree Strongly Disagree

21. Mental tough athletes make more of a difference in women's sports than in men's sports. (Circle One)

Strongly Agree Agree Disagree Strongly Disagree

22. There is a wide variety of MT training techniques. Do you incorporate any in your training? (Circle One)

Yes No 
If yes, please describe briefly:

23. If I decide to incorporate MT training, it has to be practiced a. on a regular basis, and b. in a way that its levels peak on specific dates (as physical training is). Otherwise, it is not going to be successful. (Circle One)

Strongly Agree Agree Disagree Strongly Disagree

24. What is your level of interest for knowing more about how to develop MT? (Circle One)

\begin{tabular}{|c|c|c|}
\hline Very & Somewhat & Neutral \\
\hline High & High & \\
\hline
\end{tabular}

25. MT can be practiced by a specialized professional (i.e. sport psychologist) only. (Circle One)

Strongly Agree Agree Disagree Strongly Disagree

26. Trying to develop MT at this age (18-22) is a waste of time, unless the process has started from the first involvement with the sport and/or through early adulthood. (Circle One)

Strongly Agree Agree Disagree Strongly Disagree

27. Rank in order the following dimensions of attributes of MT from 1 to 4 ( 1 being the most important).

Attitude/Mindset (i.e. belief, focus)

Training (i.e. using long-term goals as the source of motivation, controlling the environment, pushing yourself to the limit)

Competition (i.e. handling pressure, regulating performance, staying focused, awareness and control of thoughts and feelings, controlling the environment)

Post-competition (i.e. handling failure, handling success)

28. I am not sure I know what exactly MT is. (Circle One)

Strongly Agree Agree Disagree Strongly Disagree

A little bit about yourself.............

29. What is your gender? (Circle One)

Male Female

30. What is your current job title? (Circle One)

SCC Associate SCC Assistant SCC

Other (please describe): 
31. What is you academic background (degrees and certifications)?

Degrees (i.e.: BS or MS in Kinesiology):

Certifications (i.e.: CSCS, USAW):

32. How many years of experience do you have working as SCC (include years from other universities)? (Circle One)

1 year or less

$$
\begin{gathered}
2-5 \text { years } \quad 6-10 \text { years } 10-15 \text { years } \\
16-20 \text { years } 21+\text { years }
\end{gathered}
$$

33. How many years have you been training female student-athletes?

1 year or less 2-5 years 6-10 years 10-15 years

$$
\text { 16-20 years } 21+\text { years }
$$

34. How many years have you been training female basketball players?

1 year or less

$$
\begin{gathered}
2-5 \text { years } 6-10 \text { years } 10-15 \text { years } \\
16-21 \text { years 21+ years }
\end{gathered}
$$

Thank you for completing the survey! 


\section{Interview of NCAA Division 1 Strength \& Conditioning Coaches}

\section{Directions:}

This is the second of the two parts of a project investigating Big12 women's basketball strength and conditioning coaches' (SCC) opinions about mental toughness.

There are not right or wrong answers, so please respond as honestly as possible. It should not take longer than 30 minutes.

Use the following definition of mental toughness (MT) to answer the questions.

"Mental toughness is having the natural or developed psychological edge that enables you to:

- Generally, cope better than your opponents with the many demands (e.g., competition, training, lifestyle) that are placed on you as a performer.

- Specifically, to be more consistent and better than your opponents in remaining determined, focused, confident, resilient, and in control under pressure."

\section{QUESTIONS:}

1. What does mental toughness mean for you?

2. What's your opinon about the value of mental toughness?

3. Are you implenting any kind of mental toughness training?

4. Do you think that mental toughness can be developed?

5. There are several ways to measure mental toughness. Are you using any?

6. Can you indentify and rank the key issues in this area?

7. Do you think that there are gender differences when it comes to implementing mental toughness training? If so, what are they?

8. Would you be interested in learning more about mental toughness? If so, how would you go about doing this?

9. Do you think that there are any differences in the responsibilities to develop mental toughness, for you as a strength and conditioning coach, when compared to the baskeball coaches?

10. Is there anything else about mental toughness would you like to add or share? 